\title{
Using e-psychiatry to Scale up Mental Health Services in Nigeria
}

\author{
Nafisa Temilade Abdulazeez ${ }^{1 *}$ and Oladosu Ahmed Kayode ${ }^{2}$ \\ ${ }^{1}$ Maiduguri, Borno NIGERIA, University of Maiduguri, Nigeria \\ ${ }^{2}$ Department of Behavioural Sciences, University of Ilorin Teaching Hospital, Ilorin, Kwara State, Nigeria
}

A recent primary care study in Nigeria revealed that psychiatric disorders were common, with unexplained somatic complaints occurring in $57.5 \%$ of respondents, depression in 50\%, anxiety disorders $49.3 \%$, primary insomnia $45.3 \%$, and alcohol use disorder $11.3 \%$ [1]. Other studies indicate that a broad range of psychiatric disorders are seen in Nigeria including mental retardation, epilepsy, conduct disorders, substance abuse psychosis, affective disorders, substance abuse, sexual dysfunction among others [2-8]. One of the major challenges in treating mental illness in Nigeria is the dearth of mental health care facilities and mental health care professionals [9] with the result that about $70 \%$ of mental health service provision in Nigeria is delivered through non-orthodox means such as religious organisations and traditional healers [10]. In spite of this high prevalence, primary care practitioners have constraints in identifying about one-third of patients with mental health problems [11], for various reasons where the patients are able to make it to the hospital. Thus, the task of identifying and treating patients with psychiatric disorders falls on the mental health professionals.

In 2006, the world health organization conducted a study in Nigeria in which the mental health facilities were assessed in six states in the six geopolitical zones of the country [12]. The study showed that the number of human resources working in mental health facilities in the surveyed states was 3,105 . The number of professionals available to the population per 100,000 is as follows: Psychiatrists 0.15 , other medical doctors 0.49, Nurses 2.41, Psychologists 0.07, Social workers0.12, Occupational therapists 0.05 , and other health or mental health workers 8.03. Obviously from the foregoing, the number of professionals available cannot meet the needs of the populace, meaning there is a need to scale up the extent of the available mental health services. A national Literacy Survey conducted by the National Bureau of Statistics in Nigeria estimates the adult literacy rate as 56.9 percent, though with significant differences between states (Lagos $92.0 \%$ and Borno only $14.5 \%$ ), regions (urban $74.6 \%$ and rural $48.7 \%$,) and gender (male $65.1 \%$ and female $48.6 \%)$ [13].

In the last decade, internet use has become a mainstay of the life of Nigerians. As at 2011, about 45,039,711 (26.5\%) of Nigerians were using the internet [14] and this figure is likely to have increased over the years given the rate of growth of the telecoms sector in the country. These statistics suggest a good number of Nigerians can be engaged in meaningful discussions online, including discussions on mental health. The internet has several advantages in the delivery of mental health. These include but are not limited to: cost reduction; promotion of conventional service delivery, facilitation of consumer empowerment, and improved access [15].

Given the fact that mental health facilities in Nigeria are inadequate, and that it would take some time before resources especially human can be mustered, it is only logical that remedial alternative means of assessing mental health care such as the internet be sought. The advantages are enormous and will only complement manpower if manpower becomes available subsequently. The most significant advantage of e-psychiatry in a developing country like Nigeria may be in the aspect of cost reduction because even in government hospitals where treatment is taken to be relatively cheap, the consultation fee is reported anecdotally to be about five hundred naira (over 3 dollars), which when added to the cost of transportation to the health facility becomes burdensome for the patient. The cost of care delays health seeking behaviour and this increases the chances of relapse in such patients. To the knowledge of the author, there are no Nigerian forums for patients with mental health issues to relate with their caregivers. E-psychiatry will also be useful for mental health advocacy and promotion where 'well individuals' receive information on mental health promotion. Challenges to e-psychiatry will include a lack of adequate power supply, fluctuating internet service, a dearth of skilled health workers to provide the service, ethical issues especially with respect to children and possibly false alarms or prank alerts. Also, the cost of the requisite infrastructure to sustain it will challenge most developing countries. The use of electronic media to promote mental health is a part of the future of clinical practice in the third world which will also become a virtual world in the near future. Efforts must be made at the individual, organizational and governmental levels to tap into this potentially rewarding way of mental health care, through which health for all may be achieved.

\section{References}

1. Lasebikan VO, Ejidokun A, Coker AO (1993) Prevalence of Mental Disorders and Profile of Disablement among Primary Health Care Service Users in Lagos Island. Epidemiology Research International 34: 10-13.

2. Gureje $O$ (2002) Psychological disorders and symptoms in primary care: association with disability and service use after 12 months. Social Psychiatry and Psychiatric Epidemiology 37: 220-224.

3. Suleiman GT, Adeyemi SO, Adeponle AB (2006) An overview of psychoactive substance use and misuse in Northern Nigeria. Nigerian Journal of Psychiatry 4: 9-14.

4. Adegunloye OA, Yusuf AD, Ajiboye PO, Issa BA, Buhari OIN (2010) Prevalence and correlates of DistruptiveBehaviour Disorders in Youths in a juvenile Borstal Institution. Nigerian Journal of Psychiatry 8: 12-16.

5. Yussuf Ad, Ajiboye Po, Issa BA, Buhari OIN (2011) Prevalence and Risk Factors for Psychiatric Disorders among Youths In a Borstal Institution In Nigeria. Journal of Pakistan Psychiatric Society 8: 22-28.

6. Issa BA, Yussuf AD, Ajiboye PO, Adegunloye OA, Buhari OIN, et al. (2008) Pattern of Psychiatric Admission In A Nigerian Tertiary Hospital: A 5-Year Retrospective Study. Research Journal of Medical Science 2: 231-235.

7. Yussuf AD, Ajiboye PO, Buhari OIN, Kuranga SA, Balogun OR (2006) Psychological Health Problems of Resident Doctors In A Nigerian Teaching Hospital. South African Journal of Psychiatry 12: 106-111.

8. Yussuf AD, Kuranga SA, Balogun OR, Ajiboye PO, Buhari OIN (2007)

*Corresponding author: Nafisa Temilade Abdulazeez, Maiduguri, Borno NIGERIA, University of Maiduguri, Nigeria, Tel: 2348027800006; E-mail: nafisa4abdul@yahoo.com

Received February 08, 2014; Accepted March 17, 2014; Published March 22 2014

Citation: Abdulazeez NT, Kayode OA (2014) Using e-psychiatry to Scale up Mental Health Services in Nigeria. J Mass Communicat Journalism 4: 184. doi:10.4172/2165-7912.1000184

Copyright: @ 2014 Abdulazeez NT, et al. This is an open-access article distributed under the terms of the Creative Commons Attribution License, which permits unrestricted use, distribution, and reproduction in any medium, provided the original author and source are credited. 
Citation: Abdulazeez NT, Kayode OA (2014) Using e-psychiatry to Scale up Mental Health Services in Nigeria. J Mass Communicat Journalism 4: 184. doi:10.4172/2165-7912.1000184

Page 2 of 2

Psychiatric Morbidity among Nursing Staff of A University Teaching Hospital In Nigeria. Nigerian Journal of Psychiatry 5: 45-49.

9. Stephanie EU (2010) Understanding mental illness in Nigeria: Bringing culture and traditional medicine into mental health policy. Texas Medical Center Dissertations. Paper AAl1495488.

10. Oyedeji A, Oye G, Rahmaan L (2004) Psychiatric research in Nigeria: bridging tradition and modernisation. The British Journal of Psychiatry 184: 536-538.

11. Deva MP (1997) Psychiatry for the general practitioner. Medical Journal of Malaysia 52: 99-101.
12. World Health Organization (2006) A report of the assessment of the mental health system in Nigeria.

13. UNESCO (2012) Reaching the 2015 Literacy Target: Delivering on the promise. Proceedings of the High level International Round Table on Literacy. Paris, France.

14. Nigeria Internet Usage and Telecommunications Reports

15. Government Department of health. E-mental health in Australia: implications of the internet and related technologies for policy. 